\title{
Memaknai Ajaran Alkitab Tentang Keadilan Allah Dari Sudut Pandang Teologi Pentakosta
}

\author{
Kosma Manurung \\ Program Studi Magister Teologi STT Intheos Surakarta \\ kosmamanurung@sttintheos.ac.id
}

\begin{abstract}
Human social identity requires him to continue to be connected with other humans in a harmonious social relationship. The Bible also places justice as a vital part of human social life. The biblical description reveals that God is a just person and there is never fraud in God. The aim of this research is to interpret the Bible's teachings about God's justice from the perspective of Pentecostal theology. This article contains an explanation of the importance of justice for humans, the Bible's narrative about God's justice, and the way Pentecostals interpret God's justice. The method used in this research is descriptive and literature review. Based on the results of the discussion, it was concluded that in the view of the Pentecostals, God's justice speaks of God's character. The justice of Allah is also interpreted by the Pentecostals as God's Rule that God wants to be obeyed. In addition, God's justice also means the defense of Allah and the demands that God wants every believer to do in social life so that they can be maximized as witnesses of God and become salt and light for the community where God has placed.
\end{abstract}

Keywords: bible; justice; god's justice; pentecostalism; pentecostal theology

\begin{abstract}
Abstrak
Identitas sosial manusia menuntutnya untuk terus terkoneksi dengan manusia lainnya dalam sebuah hubungan sosial yang harmonis. Alkitab pun meletakkan keadilan sebagai bagian vital dalam kehidupan sosial manusia. Deskripsi Alkitab mengungkapkan bahwa Allah adalah pribadi yang adil dan tidak ada kecurangan dalam diri Allah. Tujuan penelitin ini bermaksud memaknai ajaran Alkitab tentang keadilan Allah dari sudut pandang teologi Pentakosta. Artikel ini berisi tentang penjelasan pentingnya keadilan bagi manusia, narasi Alkiab tentang keadilan Allah, dan cara kaum Pentakosta memaknai keadilan Allah. Metode yang digunakan dalam penelitian ini deskriptif dan kajian literatur. Berdasarkan hasil pembahasan ditarik kesimpulan bahwa dalam pandangan kaum Pentkosta keadilan Allah berbicara karakter Allah. Keadilan Allah juga dimaknai kaum Pentaksota sebagai Aturan Allah yang Allah ingin untuk dipatuhi. Selain itu, keadilan Allah juga dimaknai pembelaan Allah dan tuntutan yang Allah ingin setiap orang percaya lakukan dalam kehidupan bermasyarakat agar bisa maksimal sebagai saksi Tuhan dan menjadi garam serta terang bagi komunitas dimana Tuhan tempatkan.
\end{abstract}

Kata kunci: alkitab; keadilan; keadilan allah; pentakostalisme; teologi pentakosta

\section{Pendahuluan}

Yoval Noah Harari dalam bukunya Homo Sapien menjelaskan bahwa kemampuan kognitif manusia yang berevolusi membuat manusia berbeda dari binatang bahkan dari binatang yang paling dekat dengan rumpun manusia semisal Simpanse dan Bonobo (Harari, 2019). Ini artinya nalar, akal, maupun kemampuan manusia untuk berpikir sedemikian rupalah yang kemudian menjadi pembeda antara manusia dan mahluk hidup 
lainnya. Sayangnya justru kemampuan manusia untuk berpikir ini juga menjadi masalah tersendiri bagi manusia. Kejatuhan manusia di taman Eden membuktikan bahwa jika akal manusia tidak ditundukan dalam kebenaran firman Tuhan maka akan itu kenderung untuk melukai Tuhan dan melakukan hal-hal yang bertentangan dengan aturan Tuhan yang ujungnya menjadi kesengsaraan bagi manusia (Manurung, 2020c). Apa yang Alkitab nyatakan setelah peristiwa kejatuhan manusia ini semakin membuktikan kecenderugan akal manusia yang mengarah pada hal-hal negatif yang semakin menjadi-jadi setiap generasinya. Ada kalanya manusia mulai mempertanyakan keberadaan Tuhan bahkan dengan tindakan yang lebih berani lagi yaitu mengeluarkan Tuhan dalam kegiatan hidup keseharian semisal yang diceritakan dalam kisah pembangunan menara Babel (Marbun, 2020). Akan menjadi sangat berbahaya bagi sesama apabila akal manusia ini tidak ditundukan pada kebenaran Allah.

Identitas sosial manusia menuntutnya untuk terus terkoneksi dengan manusia lainnya dalam sebuah hubungan sosial yang harmonis (Xiao, 2018). Tentunya hubungan yang harmonis ini akan terbentuk jika didalamnya ada sikap saling menghormati dan bertindak dengan memperhatikan hak maupun kewajiban para pihak serta sesuai aturan yang berlaku. Ini artinya untuk terjaganya hubungan sosial yang harmonis manusia aspek keadilan adalah hal yang utama dan haruslah dikedepankan, karena apabila keadilan gagal dikedepankan maka interaksi sosial akan sangat terganggu dan bisa jadi justru chaos (Yudho \& Tjandrasari, 2017). Bicara mengutamakan bertindak adil dalam hubungan sosial, Alkitab sangat mendukung hal ini karena dibanyak kesempatan Alkitab memberikan arahan melalui para nabi-Nya supaya umat Allah dimasa lalu untuk bertindak berdasarkan keadilan (Bua, Samiyono, \& Tampake, 2019). Melalui Musa, Allah berpesan supaya bangsa Israel mengerjakan dengan benar keadilan karena atas dasar itulah mereka akan hidup di negeri yang Tuhan berikan kepada mereka (Ul. 16:20). Contoh lainnya melalui apa yang disampaikan oleh nabi Mikha, Allah menuntut orang Israel untuk melakukan hal yang baik yaitu berlaku adil (Mi. 6:8) ataupun tindakan Elia menentang apa yang raja Ahab lakukan terhadap tanah milik Nabot (1 Raj. 21).

Kitab Amsal melarang orang percaya untuk bersandar pada akal budi atau pengertiannya melainkan hanya bersandar pada Tuhan (Ams. 3:5). Prinsip Alkitab ini jelas bahwa akal, nalar, ataupun kemampuan berpikir manusia ini akan berfungsi dengan baik dan menjadi berkat apabila diselaraskan dengan kebenaran Allah (Wijaya, 2016). Tentunya kebenaran Allah yang dimaksudkan disini adalah kebenaran yang dinyatakan melalui Alkitab sebagai aturan tertinggi bagi pedoman hidup orang percaya (Katarina \& Darmawan, 2019). Seperti yang dinyatakan oleh teolog Pentakosta F.L. Arrington, kaum Pentakosta merupakan kaum yang mendasarkan pemahaman mereka pada kebenaran Alkitab (Arrington, 2020). Yang berarti apapun yang Alkitab tuliskan maka hal itu adalah keberanan yang harus dipercayai dan dihidupi termasuk juga keadilan Allah. Gambaran Alkitab yang menuntut keadilan dalam kaitan dengan interaksi sosial merupakan prinsip yang dituntut Allah untuk dilakukan oleh umat-Nya (Harefa, 2020). Sayangnya keadilan yang menjadi identitas Allah ini telah ternodai oleh banyaknya tindakan kejahatan yang dilakukan oleh manusia yang akal sehat maupun hati nuraninya telah tumpul. Mengacu 
pada latar belakang pembahasan ini, artikel ini bermaksud menjelaskan bagaimana kalangan Pentakosta memaknai keadilan Allah yang merunut pada yang Alkitab nyatakan.

\section{Metode}

Penelitian selalu membutuhkan metodologi agar memiliki landasan ilmiah yang kuat dan dapat dipertanggung jawabkan secara akademik (S. E. Zaluchu, 2021). Dalam penelitian ini peneliti menggunakan metode kualitatif dengan memaksimalkan pendekatan deskriptif dan kajian literatur. Pemilihan metode kualitatif didasarkan pada aspek kemudahan dan kecocokan dalam memperlancar penelitian, karena dalam penelitian ini peneliti ingin membangun pemahaman dan memaknai yang sangat sesuai dengan penelitian kualitatif (Zaluchu, 2020). Deskriptif digunakan untuk menjelaskan korelasi dan arti penting keadilan bagi manusia terutama dalam kaitan dengan kehidupan sosial bermasyarakat. Juga digunakan untuk mendeskripsikan sudut pandang kaum Pentekosta tentang kisah Abraham memohon keadilan Allah ketika berdoa safaat untuk kota Sodom, dan menjelaskan bagaimana kaum Pentakosta memaknai kisah tanah milik Nabot. Deskriptif juga peneliti gunakan dalam kaitan dengan pemaknaan kaum Pentakosta tentang keadilan Allah. Kajian literatur peneliti gunakan untuk memberikan topangan ilmiah terhadap ide-ide maupun gagasan peneliti sehingga memiliki dasar yang kuat secara akademik (Marzali, 2017). Adapun dalam penelitian ini literatur yang peneliti gunakan dari Alkitab, buku, dan artikel jurnal yang relevan dan memiliki nilai kebaharuan.

\section{Hasil dan Pembahasan \\ Manusia dan Keadilan}

Manusia dan keadilan seperti dua kisah yang tidak terpisahkan karena sepanjang peradaban manusia unsur keadilan selalu menjadi bagian vital dalam membangun keutuhan diri manusia (Ommen, 2019). Namun sayangnya unsur vital yang bernama keadilan ini sering tidak ditempatkan pada posisi yang seharusnya sehingga menyebabkan banyak luka, rasa sakit, bahkan sampai kematian dialami manusia (Purwendah, 2019). Sejarah di masa lalu mencatat bagaimana perlakuan para pedagang budak yang memperdagangkan manusia, membawa mereka dari akar hidup dan budaya mereka dan kemudian dijual ke negeri asing yang jauh di belahan dunia lain untuk dijadikan budak ataupun pekerja kasar. Apa yang dialami bangsa kulit hitam yang dibawa dari Afrika dan diperdagangkan ke benua Amerika adalah catatan hitam ras manusia yang menjual sesama mereka untuk alasan ekonomi dan kekuasaan satu ras terhadap ras lainnya yang melukai sekaligus juga tindakan yang memalukan dan tidak bermartabat dari manusia terhadap sesamanya (Rice, 2018). Perlu ratusan tahun sampai akhirnya warga kulit hitam khususnya di Amerika untuk merasakan keadilan dan diakui keberadaan kemanusiaan mereka seutuhnya.

Menilik sejarah manusia, nampaknya keadilan seperti mimpi bagi banyak masyarakat khususnya bangsa yang terjajah (Llewellyn Ihssen, 2018). Selalu ada kisah ketidakadilan yang terjadi ketika sebuah kerajaan menyerang kerajaan lainnya dan 
menaklukanny di bawah panji kekuasaannya. Pada zaman kuno, penaklukan ini biasa disertai dengan pembantaian kaum pria, penjarahan harta benda, bahkan tak jarang disertai dengan banyaknya pemerkosaan, dan penawanan (Suliyati, 2018). Tawanan perang kemudian menjadi budak, dipekerjakan dengan tidak manusiawi, dalam kasuskasus tertentu mereka kemudian dijual atau malah dibunuh apabila terdapat sedikit saja kesalahan kecil. Bagaimana jadinya anak-anak yang orang tuanya dibunuh di depan mata, ibu dan kakak perempuan mereka diperkosa, harta benda mereka dirampas dan para penjajah itu membanggakan perbuatan bejatnya, dan yang lebih menyedihkan ada dari anak-anak ini akhirnya ditinggal begitu saja tanpa tahu apa yang harus dimakan dan kepada siapa akan menyandarkan hidup selanjutnya (Prihatina, Sukarno, \& Markamah, 2018).

Sejarah juga mencatat bagaimana sebagai sebuah bangsa, Indonesia juga mengalami apa yang dinamakan ketidakadilan itu. Selama sekitar tiga setengah abad bangsa ini mengalami penjajahan dari bangsa Belanda yang nota bane nya mengidentikan diri dengan bangsa mayoritas agama Kristen dan mengakui Alkitab sebagai kebenaran Allah (Achsani, 2020). Selama penjajahan belanda, bangsa ini mengalami banyak ketidak adilan yang melahirkan luka emosi, korban perasaan, perampasan harta, tak jarang karena alasan tertentu ada orang yang akhirnya dituduh pemberontak dan dieksekusi paksa. Ketidak adilan ini kemudian melahirkan banyaknya perlawanan dari pemimpinpemimpin lokal semisal Patimura di Maluku, Sisingamangaraja di Sumatera Utama, Cut Nyak Dien di Aceh, Imam Bonjol di Sumatera Barat, Diponegoro di Jawa, dan masih banyak lainnya namun kesemuanya bisa diredam oleh pemerintahan Hindia Belanda. Namun perlawanan di bumi pertiwi terus berlanjut, ada kemudian karena bersuara lantang menentang penjajahan dan ketidak adilan harus mengalami pembuangan dan diasingkan ke berbagai tempat sepi seperti yang dialami banyak pejuang kemerdekaan seperti Seokarno, Hatta, dan yang lainnya (Kalim, 2017).

Ketika akhirnya Indonesia mengalami kemerdekaan, harus diakui ada ketidakadilan yang masih terjadi diantara sesama anak bangsa (HANAFI, 2018). Peristiwa 98 yang merembes ke penjarahan dan pembakaran serta pemerkosaan yang dialami saudara sesama anak bangsa dari etnis Tionghoa, masih adanya kerusuhan antar suku yang terjadi di Kalimantan Barat dan Kalimantan Tengah, kerusuhan berbau Agama yang terjadi di Palu, Poso, dan Maluku. Banyak dari mereka tidak tahu menahu, tidak terlibat, yang akhirnya menjadi korban dari kebrutalan dan ketidakadilan dari segelintir pihak yang memainkan situasi demi mendapatkan keuntungan darinya. Ada orang-orang yang karena koneksi maupun kekuasaan dengan mudahnya dari mempolitisasi kasus sampai memutar balikan hukum dan keadilan sehingga yang terlihat hukum hanya menyasar orang atau golongan tertentu. Apa yang di alami Ahok beberapa tahun lalu misalnya adalah contoh nyata bagaimana kekuatan golongan tertentu bisa mengiring opini hukum. Ataupun dalam kasus pelarangan ibadah atau penutupan paksa gereja yang terjadi GKI Yasmin di Bogor, Gereja Pentakosta Ciranjang dan beberapa gereja lainnya menunjukan bahwa gereja Tuhan pun mengalami ketidakadilan itu. Contoh-contoh ini menunjukan bagaimana sebagai bangsa masih harus terus belajar merawat kemerdekaan dengan 
mengedepankan keadilan bagi semua warga masyarakat yang merupakan aplikasi nyata dari dasar negara kita yaitu sila ke- 5 dari Pancasila (Sulistyorini, 2020).

Kekuatan dan kekuasaan di tangan orang yang hatinya jahat sudah terlalu banyak melahirkan ketidakadilan yang menumpahkan darah orang baik, murni, jujur, dan tidak bersalah (Ramadhan, Darmawan, \& Iriyadi, 2017). Untuk itu sebagai orang yang memahami sejarah masa lalu adalah baik apabila bertindak dengan bijaksana ketika dianugerahi kekuasaan atau jangan pernah memberikan kekuasaan pada orang yang tidak tepat karena akan melahirkan ketidakadilan lainnya (Toganti, 2019). Melihat semua ketidakadilan yang telah terjadi baik di masa lalu maupun masa kita hidup ini, barangkali ada banyak pemikiran yang terlindas dari mahluk pemikir bernama manusia terkait dengan sikap Allah. Apakah Allah tidak peduli dengan ketidak adilan, orang yang tertindas, dan kaum yang rentan dalam masyarakat? Pembahasan selanjutnya terkait dengan narasi Alkitab akan menjawab tuntas pandangan Allah tentang ketidak adilan.

\section{Narasi Alkitab Tenang Keadilan Allah}

Deskripsi Alkitab mengungkapkan bahwa Allah adalah pribadi yang adil dan tidak pernah akan ditemukan kecurangan dalam diri Allah (Ul. 32:4; Maz 7:12; 11:7; Yes. 30:18; Zef: 3:5; Yoh: 17:25). Hal tersebut adalah bagian dari karakter-Nya dan dapat teramati ketika berhubungan dengan manusia hubungan pencipta-ciptaan (Hultgren, 2019). Ini artinya bagi Allah, keadilan adalah sesuatu yang sangat penting dan harus, begitu juga hal ini Allah tuntut dari manusia ketika berhubungan dengan Allah maupun dengan sesama. Kisah doa syafaat Abraham untuk kota Sodom merupakan sebuah penjelasan yang baik bagaimana dengan daya pikirnya manusia dalam hal ini Abraham mulai meletakan landasan permohonan doanya pada keadilan Tuhan (Nayuf, 2019). Abraham dalam Kejadian 18:25 berkata masakan Hakim segenap bumi tidak menghukum dengan adil? Mengacu pada bahasa asli Ibrani kata adil juga bisa dimaknai sebagai bertindak jujur berdasarkan ukuran pas dalam memutuskan sesuatu. Terlihat dalam perikop syafaat untuk kota Sodom ini, Abraham berusaha memohon kepada Allah berdasarkan keadilannya untuk tidak memberikan ukuran yang berbeda antara orang saleh dan orang fasik (Ngahu, 2019). Bagi Abraham jelas tidak adil kalau Allah menghukum orang benar karena kesalahan orang fasik atau memberikan hukuman yang sama antara orang benar dan orang fasik.

Narasi lainnya tentang keadilan Allah di Alkitab dapat ditemukan dalam Ulangan 16:20 di mana dengan sangat jelas penulis kitab Ulangan mengambarkan bahwa Allah begitu menghendaki para pemimpin yaitu hakim-hakim yang diangkat untuk mengadili umat haruslah benar-benar mengedepankan keadilan dalam setiap keputusan mereka (Houston, 2005). Karena para hakim ini akan mengadili dan menjaga ketertiban serta keteraturan masyarakat, maka keadilan sangatlah penting untuk terpeliharanya keamanan, ketertiban, dan keteraturan dalam masyarakat Israel waktu itu. Gambaran penekanan Alkitab ini jelas dan solusi cerdas dari Allah yang maha bijaksana yang begitu menghendaki keadilan karena ketika terpelihara pada level sosial kemasyarakatan maka akan tercipta rasa aman dan ketertiban pasti terpelihara (Samarenna, 2019). 
Kisah Nabot dalam 1 Raja-raja 21 merupakan kisah yang sangat relevan terkait penekanan Allah melalui Alkitab tentang keadilan. Tanah milik Nabot ini terletak berdampingan dengan istana raja Ahab di Yisreel, tentunya tanah ini adalah merupakan tanah warisan dari leluruh yang bagi Nabot memiliki nilai sejarah yang sangat tinggi dan harus di jaga serta dirawat dengan baik (Dase, 2019). raja Ahab sangat menginginkan tanah itu, sehingga menawari Nabot dengan uang yang sangat besar untuk membeli tanah itu dan sayangnya ditolak oleh Nabot. Lewat solusi licik sang Istri yaitu Izebel akhirnya raja Ahab menemukan cara untuk memiliki tanah itu dengan memfitnah Nabot melaluk kesaksian orang dursila yang dibayar dengan tuduhan Nabot telah menghujat Allah dan raja. Allah sangat tidak suka akan hal ini dan sangat menentang perbuatan Ahab ini, Allah melalui nabi Elia kemudian menyatakan penghukuman yang ditujukan terhadap Ahab dan istrinya (Manurung, 2020a). Beberapa tahun kemudian raja Ahab terbunuh dalam perang, dan beberapa waktu berselangan istrinya mati dengan cara sangat mengenaskan sesuai dengan nubuat Elia sang nabi Allah. Terkait dengan narasi pencaplokan tanah Nabot oleh raja Ahab ini, Naim Stifan Ateek seorang teolog Kristen Palestina dalam bukunya Semata-mata Keadilan menyatakan bahwa Allah tidak pernah kompromi dengan yang namanya ketidakadilan (Ateek, 2009).

Keadilan juga menjadi tema sentral dalam Perjanjian Baru baik itu terkait dengan Allah maupun dalam kaitan dengan manusia dan semamanya (Nel, 2018). Penulis Kitab Yohanes ketika membicarakan topik doa Tuhan Yesus untuk murid-muridnya, menamai Allah sebagai Bapa yang Adil (Yoh. 17:25). Tuhan Yesus adalah contoh yang sempurna bagaimana seharusnya keadilan itu dinyatakan dalam keseharian, ketegasannya membela perempuan yang dituduh dengan dakwaan kedapatan berbuat jinah tanpa putusan pengadilan yang sah dan tentunya si wanita ini dijatuhi putusan tanpa mempertimbangkan alat bukti yang kuat yang secara hukum itu sangat menciderai hukum dan keadilan (Rumahorbo, 2020). Contoh lainnya apa yang Tuhan Yesus lakukan terhadap terhadap anak-anak ketika ada orang tua ingin supaya Tuhan meletakan tangannya atas mereka, para murid menghalang-halangi dan tidak sekedar menghalangi penulis kitab Matius mengambarkan dengan sangat detail bahwa para murid Memarahi orang itu namun Tuhan Yesus membela dengan menyatakan biarkanlah anak-anak itu datang kepada Ku (Mat. 19:13-14). Sebuah pemandangan yang agak ironis memang melihat apa yang Tuhan Yesus lakukan kepada anak-anak ini, kalau dibandingkan dengan para hamba Tuhan besar masa kini yang belum tentu mau direpotkan hanya untuk datang dan melayani anak-anak kecil yang tidak seberapa jumlahnya (ALAKAMAN, 2018). Rasul Paulus dalam suratnya kepada jemaat di Korintus, ketika membahas topik mencari keadilan terhadap orang-orang yang tidak seiman menyatakan dengan lantang pentingnya orang percaya berbuat adil dan mengaitkan keadilan dengan kerajaan Allah, Paulus berkeyakinan bahwa orang yang tidak berlaku adil tidak layak masuk dalam Kerajaan Allah (1 Kor. 6:9). 


\section{Cara Kaum Pentakosta Memaknai Keadilan Allah}

\section{Karakter Allah}

Keadilan yang Alkitab gambarkan tentang Allah adalah sesuatu yang lahir dari Karakter Allah itu sendiri (Sunarko, 2019). Karaker adalah sesuatu yang melekat pada diri individu dan karakter ini akan sangat terlihat apabila ada sesuatu yang menekan prinsip, perasaan maupun akal seseorang (Nainggolan \& Ma, 2019). Ini artinya karakter diri seseorang adalah bagian terdalam dari dirinya yang secara natural sudah melebur dan menjadi respon yang akan dikeluarkan ketika menanggapi sesuatu. Bagi Allah, keadilan adalah sesuatu yang secara lahiriah akan selalu ada dalam setiap tindakan Allah. Dari penjelasan sebelumnya bagaimana Alkitab menempatkan kebenaran Allah selalu berjalan dengan keadilan-Nya dan ketika keadilan tidak ada maka secara langsung hal itu berdampak pada ternodanya kebenaran Allah (Wagner, 2019). Kalangan pentakosta meyakini benar bahwa Allah tidak bisa dipisahkan dari keadilan-Nya (William Oliverio, 2020). Minggus Pranoto mengungkapkan beberapa dekade terakhir teologi Pentakosta tidak sekedar membicarakan hal-hal rohani saja melainkan mendarat pada isu-isu praktis kehidupan manusia termasuk juga politik dan keadilan sosial (Pranoto, 2019). Teolog Pentakosta lainnya, Amos Yong menyarankan gereja Tuhan dalam hal ini orang percaya untuk terlibat aktif bukan sekedar di gedung gereja tapi juga bergerak ke luar gedung gereja untuk menerangi komunitas sekitar juga dunia politik dimana hukum dan keadilan itu dibentuk sehingga nilai-nilai kebenaran diperjuangkan (von Sinner, 2012). Pandangan Amos Yong yang mendesak orang percaya untuk tidak anti dengan politik melainkan harus terlibat menerangi dunia politik sangatlah tepat agar rancangan dan keadilan Tuhan bisa terlaksana.

Dalam pandangan masyarakat modern, keadilan juga dilihat sebagai unsur utama dalam menjaga keamanan dan ketertiban baik itu dalam aspek hukum maupun dalam pergaulan bermasyarakat (Utomo, 2020). Hukum tidak akan berfungsi dengan benar mana kala didalamnya mengabaikan aspek keadilan dalam setiap keputusannya (Galih, 2017). Ketika hukum hanya berpihak pada yang kaya dan menyasar yang lemah maka cepat atau lambat kekacauan akan terjadi. Ketika yang kuat bisa bertindak semena-mena terhadap yang lemah dan hukum gagal menunjukan keadilan maka perasaan masyarakat terlukai dan pastinya dalam sanubari mereka menuntut keadilan. Siahaan melihat bahwa pandangan kaum Pentakosta tidak bisa dipisahkan dari dinamika kehidupan Kristen dan (Siahaan, 2017). Membingkai apa yang diungkap oleh Siahan, Pranoto, dan Amos Yong maka narasi Alkitab yang melekatkan keadilan Allah pada karakter-Nya bagi kaum Pentakosta adalah sesuatu yang sangat esensi sifatnya karena ketika karakter Allah dilepaskan dari keadilan maka tidak akan pernah lagi ada keadilan.

\section{Aturan Allah}

Keadilan Allah juga dimaknai kalangan Pentakosta sebagai aturan Allah yang harus ditaati (Davies, 2018). Alkitab mengambarkan bahwa Allah yang merupakan pencipta segala sesuatu itu menginginkan agar keadilannya diberlakukan diseluruh penjuru bumi, ini artinya setiap manusia harus berjalan dalam aturan keadilan itu (Munthe, 2019). 
Bertindak adil artinya memutuskan bertindak sesuai dengan aturan dan ketentuan yang berlaku dan apabila aturan atau ketentuan itu dilanggar maka rasa keadilan pasti dilukai. Tindakan adil yang dituntut disini tentunya dalam kaitan dengan tindakan sosial seseorang maksudnya tindakan yang dilakukan oleh seseorang dalam kaitan sebagai bagian dari anggota masyarakat maupun sebagai warga negara (Duryadi, 2017).

Alkitab menulis bagaimana Allah memberikan aturan dasar yang harus dipatuhi oleh setiap pemimpin dalam hal ini hakim yang akan mengadili setiap perkara yang terjadi dalam kehidupan umat pilihan waktu itu (Manurung, 2020a). Allah ingin agar setiap pengadil ini bertindak mengutamakan keadilan dalam setiap keputusan mereka (Ul. 16: 18-20). Revolusi Prancis dengan liberte, egalite, fraternite juga menuntut adanya keadilan dalam kehidupan sosial, hukum dan kemasyarakatan yang akhirnya banyak menjadi inspirasi akan keadilan dan hukum dalam negara modern (Christmas \& Purwanti, 2020). Sebagai bangsa, Indonesia juga menjunjung tinggi asas keadilan ini dimana dalam sila ke lima Pancasila, keadilan harus diwujud nyatakan bagi seluruh rakyat Indonesia. Pasal 27 ayat 1 UUD 1945 mengokohkan bahwa semua warga negara bersamaan kedudukannya dalam hukum, ini berarti setiap warga negara memiliki hak untuk diperlakukan adil baik oleh pemegang kekuasaan maupun sesama anak bangsa karena di depan hukum semuanya sama. Berkaca pada pandangan Lukas, Siahaan dengan tegas menolak jika pandangan Pentakosta hanya berbicara tentang perkara rohani saja melainkan juga harus hidup dalam nasionalisme (Siahaan, 2018). Zaluchu berpandangan bahwa hukum Tuhan melarang manusia untuk bertindak jahat tetapi memerintahkan manusia untuk melakukan kasih dan keadilan (Zaluchu, 2018). Seperti yang dikatakan Arrington sebagai penegasan pandangan kaum Pentakosta bahwa Allah itu baik, tetapi orang percaya saat ini tinggal di dunia yang menderita (Arrington, 2020). Pancasila adalah aturan hukum tertinggi yang diberikan Tuhan untuk bangsa ini. Apabila ketiga pandangan teolog Pentakosta ini dijalin maka nasionalisme dalam bingkai Pancasila berarti hidup dalam aturan dan ketetapan hukum yang berlaku dibangsa ini yang menjunjung tinggi keadilan sosial bagi seluruh rakyat Indonesia. Orang percaya wajib untuk taat dan patuh serta berusaha untuk berperilaku dengan adil sesuai dengan aturan yang berlaku terutama aturan ilahi yang dianjurkan Allah melalui Alkitab.

\section{Tindakan Pembelaan Allah}

Aturan hukum ditegakkan akan memberikan rasa aman dan terlindungi kepada warga masyarakat yang berada dibawah aturan tersebut, namun ketika aturan itu hanya menyasar satu golongan maka akan melukai rasa keadilan (Yudho \& Tjandrasari, 2017). Bicara keadilan tidak sekedar dalam upaya penegakan aturan yang berlaku sama rasa maupun sama rata melainkan juga keadilan juga dimaksudkan sebagai upaya pembelaan terhadap pihak yang hak-haknya terkungkung, terlanggar, bahkan dirampas (Nurita, 2015). Ketika ketidak sesuaian dan pelangaran aturan ini terjadi, maka semua mata akan melihat dan menunggu bagaimana reaksi pihak yang berwewenang untuk menegakan keadilan ini. Seperti kata Alkitab dalam Roma 13:1-4, Allah menenetapkan pemerintah 
untuk menegakan keadilan dan pemerintah adalah perpanjangan tangan Allah untuk membalas mereka yang berbuat jahat (Zaluchu, 2018).

Sayangnya tidak semua pemerintah memahami bahwa mereka adalah perpanjangan tangan Allah untuk memberikan penghukuman kepada para pembuat kejahatan yang telah merusak rasa keadilan di masyarakat (Sholahudin, 2019). Apa yang terjadi terhadap Nabot, menjelaskan kadang malah orang yang memegang kekuasaan malah yang menjadi sumber bencana ketidak adilan itu. Sejarah peradaban manusia menunjukan, banyak pemegang tambuk kekuasaan malah memposisikan diri mereka sebagai pihak yang memberengus keadilan dan berbuat semaunya mengambil harta benda, mengusir, bahkan membunuh (Ramadhan et al., 2017). Apa yang di lakukan Hitler terhadap orang Yahudi, dan para diktator maupun tiran lainnya yang mengeruk keuntungan sedemikian rupa pada masa pemerintahan mereka hanya untuk diri pribadi dan golongan merupakan contoh lainnya bahwa kadang bukannya menegakan keadilan tapi pihak berkuasa malah pencipta ketidakadilan.

Selina Stone dalam tulisannya tentang Pentecostal Power menyatakan bahwa kegiatan gereja seharusnya berdampak pada kehidupan publik dengan membela orangorang teraniaya dan menunjukan keadilan sehingga mengantarkan pembebasan rohani, sosial, dan politik (Stone, 2018). Senada dengan itu teolog Pentakosta lainnya, David Muir dalam tulisannya Pentecostalism \& Socio-Political Engagement menuturkan gereja sebagai garam dan terang dunia tidak boleh lagi acuh tak acuh melainkan harus terlibat aktif dalam politik budaya masyarakat setempat dan menawarkan sebuah konsep penyatuan politik dan doa (Muir, 2018). Seperti Allah membela bangsa Israel dalam ketidak adilan dan penindasan di Mesir, Allah yang sama juga membela Nabot dari tangan raja Ahab dan menunjukan Keadilan-Nya, Mengacu pandangan Stone dan Muir yang mewakili kaum Pentakosta, sudah sepantasnya gereja Tuhan meyakini bahwa keadilan Allah juga berbicara tentang pembelaan Allah dan Allah.

\section{Tuntutan Allah}

Melalui nabi Mikha, Allah begitu tegas menyatakan dan memerintahkan untuk setiap orang berlaku adil (Mik.6:8). Kaum Pentakosta juga memaknai keadilan Allah sebagai tuntutan Allah pada setiap tindakan manusia dalam kehidupan mereka bermasyarakat secara khusus bagi orang percaya (Sunarko, 2019). Artinya seseorang tidak bisa bertindak semaunya apalagi dalam konteks tindakan sosial, orang tersebut harus mempertimbangkan dengan saksama rasa keadilan masyarakat karena jika tidak orang tersebut akan berhadapan dengan tuntutan hukum, yang dalam hal ini dipahami oleh kaum Pentaksota sebagai tuntutan Allah melalui wakil-Nya yaitu pemerintah yang Dia tetapkan (Manurung, 2020b).

Siahaan memaknai kaum Pentakosta sebagai kaum yang melandaskan praktek hidup berdasarkan apa yang dinyatakan Alkitab dan berusaha menyelaraskannya dengan Alkitab (Siahaan, 2017). Terhadap tuntutan Allah untuk berlaku adil ini maka tidak ada cara lain kecuali mentaati dan mengupayakan semampu yang orang percaya bisa lakukan (Siagian, 2019). Mengamati apa yang Alkitab nyatakan, setiap kali ketidak adilan meraja 
lela maka Allah akan mengutus hamba-Nya maupun para nabi-Nya untuk mengugat tindakan ketidak adilan itu (Wood, 2005). Ketika ketidak adilan meraja lela adalah bukan pilihan bagi orang percaya maupun gereja Tuhan untuk tetap diam saja. Sikap diam gereja harus dikritisi, sikap diam waktu perdagangan budak, sikap diam waktu penjajahan dan kolianlisasi di banyak negara asia, dan sikap diam gereja modern saat ini dengan banyaknya ketidakadilan yang terjadi.

Arrington dalam bukunya Doktrin Kristen Perspektif Pentakosta menyatakan bahwa kurangnya kasih manusia terhadap sesama nenunjukkan keterasingan seseorang dari Allah (Arrington, 2020). Daniel Sutoyo berpendapat bahwa gerakan Pentakosta adalah gerakan yang berkarakteristik merestorasi (Sutoyo, 2018). Melihat bagaimana gerakan Pentakosta lahir dengan meletakan nilai keadilan dalam ibadah di mana tidak ada lagi perbedaan warna kulit maupun jenis kelamin, namun semuanya sama di mata Tuhan. Artinya gerakan ini kemudian mendapatkan dukungan melalui mimpi Martin Luther King, Jr yang memimpikan kesetaraan antara kulit putih dan kulit hitam di Amerika. Menyatukan pandangan Siahaan, Sutoyo, dan Arrington didapati kesimpulan bahwa sebagai gereja Tuhan di masa ini, kalangan Pentakosta beranggapan orang percaya seharusnya menempatkan diri sebagai agen dari keadilan Allah, maksudnya orang yang mengupayakan sedemikian rupa agar keadilan Allah yang dituntut oleh Alkitab menjadi bagian penting dalam kehidupan keseharian.

\section{Implikasi}

Implikasi yang dapat diungkapkan dalam tulisan ini menyatakan bahwa Alkitab dalam pandangan kaum Pentakosta memberikan landasan pijak yang kuat bahwa Allah ingin keadilan dinikmati dan dilakukan oleh setiap orang. Dalam pandangan kaum Pentkosta, keadilan Allah berbicara karakter Allah. Artinya ketika Alkitab merujuk pada keadilan yang Allah inginkan, itu merupakan hal yang tidak dapat dipisahkan dari kepribadiaan Allah yaitu yang merupakan karakternya untuk selalu berlaku adil. Keadilan Allah juga berbicara tentang aturan yang Allah tetapkan untuk dipatuhi. Keadilan Allah merupakan tuntutan Allah yang Allah ingin setiap orang percaya lakukan dalam kehidupan bermasyarakat agar bisa maksimal sebagai saksi Tuhan dan menjadi garam serta terang bagi komunitas dimana Tuhan tempatkan.

\section{Rekomendasi untuk Penelitian Lanjutan}

Rekomendasi untuk penelitian lanjutan dapat dilakukan dengan melihat sudut pandang yang berbeda (selain teologi pentakota) tentang keadilan Allah. Kemudian, dapat juga mengembangkannya dengan kajian yang lebih dalam, seperti wawancawa mendalam kepada tokoh-tokoh terkait tentang keadilan Allah dalam kehidupan praktis.

\section{Kesimpulan}

Manusia dan keadilan seperti dua bagian yang tidak terpisahkan karena sepanjang peradaban manusia unsur keadilan selalu menjadi bagian vital dalam membangun keutuhan diri manusia terutama dalam kaitan dengan kehidupan bermasyarakat. 
Identitas sosial manusia menuntutnya untuk terus terkoneksi dengan manusia lainnya dalam sebuah hubungan sosial yang harmonis. Tentunya hubungan yang harmonis ini akan terbentuk jika didalamnya ada sikap saling menghormati dan bertindak dengan memperhatikan hak maupun kewajiban para pihak serta sesuai aturan yang berlaku sehingga rasa keadilan didahulukan dan dihormati. Alkitab dalam pandangan kaum Pentakosta memberikan landasan pijak yang kuat bahwa Allah ingin keadilan dinikmati dan dilakukan oleh setiap orang. Mengacu pada hasil pembahasan artikel ini dapatlah ditarik kesimpulan bahwa dalam pandangan kaum Pentkosta keadilan Allah berbicara karakter Allah. Artinya ketika Alkitab merujuk pada keadilan yang Allah inginkan, itu merupakan hal yang tidak dapat dipisahkan dari kepribadiaan Allah yaitu yang merupakan karakternya untuk selalu berlaku adil. Keadilan Allah juga berbicara tentang aturan yang Allah tetapkan untuk dipatuhi. Selain itu, keadilan Allah dimaknai pembelaan Allah sebagaimana yang dicontohkan dalam kasus tanah milik Nabot, Allah melalui nabi Elia menyerukan bahwa tindakan yang raja Ahab dan istrinya Izebel itu tidak adil dan Allah menentang tindakan mereka serta menyerukan penghukuman-Nya. Keadilan Allah merupakan tuntutan Allah yang Allah ingin setiap orang percaya lakukan dalam kehidupan bermasyarakat agar bisa maksimal sebagai saksi Tuhan dan menjadi garam serta terang bagi komunitas dimana Tuhan tempatkan. Kiranya hasil penelitian ini bisa menambah banyak daftar literasi dan memperkaya khasanah ilmu teologi secara khusus teologi Pentakosta, dan juga jadi inspirasi bagi para peneliti untuk membuat penelitian yang terkait maupun beririsan dengan topik pembahasan artikel ini, atau menjadikannya bahan rujukan.

\section{Rujukan}

Achsani, F. (2020). MASYARAKAT PRIBUMI PADA MASA PENJAJAHAN BELANDA DALAM NOVEL KISAH TANAH JAWA KARYA MADA ZIDAN DAN BONAVENTURA DE GENTA. SALINGKA, 17(1), 15-28. https://doi.org/10.26499/salingka.v17i1.266

ALAKAMAN, M. T. (2018). YESUS SEBAGAI HAMBA Kajian Kristologi Dan Relevansinya Pada Pelayan Gereja Di Jemaat GPM Nehemia Sektor Petra. KENOSIS: Jurnal Kajian Teologi, 4(1), 15-34. https://doi.org/10.37196/kenosis.v1i1.20

Arrington, F. L. (2020). DOKTRIN KRISTEN PERSPEKTIF PENTAKOSTA. Yogyakarta: ANDI Offset.

Ateek, N. S. (2009). Semata-mata Keadilan. Jakarta: BPK Gunung Mulia.

Bua, P. R., Samiyono, D., \& Tampake, T. C. (2019). Misi Gereja dalam Mewujudkan Keadilan Sosial: Sebuah Perspektif dari Sila Kelima Pancasila. KURIOS (Jurnal Teologi Dan Pendidikan Agama Kristen), 5(2), 109-124. Retrieved from http://www.sttpb.ac.id/e-journal/index.php/kurios/article/view/97/71

Christmas, S. K., \& Purwanti, E. (2020). Perkembangan Sistem Pemerintahan dan Konsep Kedaulatan Pasca Revolusi Perancis Terhadap Hukum Internasional. Jurnal Pembangunan Hukum Indonesia, 2(2), 222-235.

https://doi.org/10.14710/jphi.v2i2.222-235

Dase, A. B. (2019). Kontribusi Hermeneutis 1 Raja-Raja 21 terhadap Konflik Agraria di 
Indonesia. BIA': Jurnal Teologi Dan Pendidikan Kristen Kontekstual, 2(1), 40-54. https://doi.org/10.34307/b.v2i1.88

Davies, A. (2018, January 2). Pentecostals and social and political engagement. Journal of the European Pentecostal Theological Association, Vol. 38, p. 1.

https://doi.org/10.1080/18124461.2018.1440458

Duryadi, M. (2017). DINAMIKA HUBUNGAN ANTAR AGAMA DAN MASYARAKAT. Jurnal Abdiel: Khazanah Pemikiran Teologi, Pendidikan Agama Kristen, Dan Musik Gereja, 1(01), 55-69. https://doi.org/10.37368/ja.v1i01.86

Galih, Y. S. (2017). KEWAJIBAN NEGARA MELINDUNGI ANAK BANGSA. Jurnal Ilmiah Galuh Justisi, 5(1), 113. https://doi.org/10.25157/jigj.v5i1.249

HANAFI, H. (2018). HAKEKAT NILAI PERSATUAN DALAM KONTEKS INDONESIA (Sebuah Tinjauan Kontekstual Positif Sila Ketiga Pancasila). Jurnal Ilmiah Pendidikan Pancasila Dan Kewarganegaraan, 3(1), 56-63. https://doi.org/10.17977/um019v3i12018p056

Harari, Y. N. (2019). Sapiens Riwayat Singkat Umat Manusia. Jakarta: KPG (Kepustakaan Populer Gramedia).

Harefa, O. N. (2020). Ketika Keadilan Bertemu Dengan Kasih. SUNDERMANN: Jurnal Ilmiah Teologi, Pendidikan, Sains, Humaniora Dan Kebudayaan, 13(1), 39-47. https://doi.org/10.36588/sundermann.v13i1.31

Houston, W. J. (2005). The Character of Yhwh and the Ethics of the Old Testament: is Imitatio Dei Appropriate? The Journal of Theological Studies, 58(1), 1-25. https://doi.org/10.1093/jts/fll036

Hultgren, S. (2019). Hilastērion (Rom. 3:25) and the Union of Divine Justice And Mercy. Part II: Atonement in the old Testament and in Romans 1-5. The Journal of Theological Studies, 70(2), 546-599. https://doi.org/10.1093/jts/flz082

Kalim. (2017). PENERAPAN COOPERATIF LEARNING PADA MATERI POKOK KETELADANAN TOKOH PROKLAMATOR KEMERDEKAAN REPUBLIK INDONESIA. Jurnal Inovasi Pembelajaran Karakter, 2(1), 1-10. Retrieved from http://irpp.com/index.php/jipk/article/view/729

Katarina, K., \& Darmawan, I. P. A. (2019). Alkitab dalam Formasi Rohani pada Era Reformasi Gereja dan Implikasi bagi Gereja Pada Masa Kini. EPIGRAPHE: Jurnal Teologi Dan Pelayanan Kristiani, 3(2), 81. https://doi.org/10.33991/epigraphe.v3i2.85

Llewellyn Ihssen, B. (2018). Social Justice and the Legitimacy of Slavery: The Role of Philosophical Asceticism from Ancient Judaism to Late Anquity. By Ilaria L. E. Ramelli. The Journal of Theological Studies, 69(1), 318-320. https://doi.org/10.1093/jts/flx202

Manurung, K. (2020a). Ketubim dan Nubuat. Pengarah: Jurnal Teologi Kristen, 2(2), 129140. https://doi.org/10.36270/pengarah.v2i2.24

Manurung, K. (2020b). MEMAKNAI KEMARAHAN ALLAH DARI SUDUT PANDANG TEOLOGI PENTAKOSTA DI ERA POST MODERN. VISIO DEI: JURNAL TEOLOGI KRISTEN, 2(2), 307-328. 
https://doi.org/https://doi.org/10.35909/visiodei.v2i2.162

Manurung, K. (2020c). Taurat dan Nubuat Palsu: Kajian Sudut Pandang Taurat Terhadap Nubuat Palsu. Jurnal Teologi Berita Hidup, 2(2), 94-109.

https://doi.org/10.38189/jtbh.v2i2.31

Marbun, P. (2020). Konsep Dosa dalam Perjanjian Lama dan Hubungannya dengan

Konsep Perjanjian. CARAKA: Jurnal Teologi Biblika Dan Praktika, 1(1), 1-16.

https://doi.org/10.46348/car.v1i1.9

Marzali, A.-. (2017). Menulis Kajian Literatur. ETNOSIA : Jurnal Etnografi Indonesia, 1(2),

27. https://doi.org/10.31947/etnosia.v1i2.1613

Muir, R. D. (2018). Pentecostalism \& socio-political engagement: Aprolegomenon for the common good. Journal of the European Pentecostal Theological Association, 38(2), 165-182. https://doi.org/10.1080/18124461.2018.1484988

Munthe, E. (2019). Implikasi Penggunaan "El"dan "YHWH" dalam Kekristenan Masa Kini. KURIOS (Jurnal Teologi Dan Pendidikan Agama Kristen), 5(1), 54-73.

Nainggolan, C. B., \& Ma, D. S. (2019). FONDASI TEOLOGIS UNTUK PENDIDIKAN KARAKTER BERDASARKAN 'PEMBENARAN OLEH IMAN' MARTIN LUTHER. STULOS, 17(1), 1-27. Retrieved from http://www.sttb.ac.id/download/stulos/stulos-v17-no01/1

Nayuf, H. (2019). Politisasi Doa: Menalar Pilihan Politik Abraham Terhadap Sodom. KENOSIS: Jurnal Kajian Teologi, 5(2), 112-177. https://doi.org/10.37196/kenosis.v5i2.79

Nel, M. (2018). Pentecostal ecumenical impulses: Past and present challenges. In Die Skriflig/In Luce Verbi, 52(1), 8. https://doi.org/10.4102/ids.v52i1.2330

Nel, M. (2020). Pentecostal canon of the bible? Journal of Pentecostal Theology, 29(1), 115. https://doi.org/10.1163/17455251-02901001

Ngahu, S. S. T. (2019). Menguak Prasangka Homoseksualitas dalam Kisah Sodom dan Gomora: Kajian Hermenutik Kejadian 19:1-26. GEMA TEOLOGIKA: Jurnal Teologi Kontekstual Dan Filsafat Keilahian, 4(1), 17. https://doi.org/10.21460/gema.2019.41.406

Nurita, R. F. (2015). Kajian Filsafat Hukum Tentang Demokrasi Di Indonesia. Jurnal Cakrawala Hukum.

Pranoto, M. M. (2019). “DISCERNING THE SPIRIT (S)” DALAM KUASA POLITIK: SEBUAH PERSPEKTIF TEOLOGI PENTAKOSTAL. Jurnal Abdiel: Khazanah Pemikiran Teologi, Pendidikan Agama Kristen, Dan Musik Gereja, 3(1), 1-16. https://doi.org/10.37368/ja.v3i1.33

Prihatina, S. A., Sukarno, S., \& Markamah, E. S. (2018). THE IMPROVEMENT OF THE INTERESEST IN LEARNING SOCIAL SCIENCES USING JOYFUL LEARNING STRATEGY SUPPORTED BY FUN SOCIAL PUZZLE MEDIA. Social, Humanities, and Educational Studies (SHEs): Conference Series, 1(1), 793-798.

https://doi.org/10.20961/shes.v1i1.23682

Purwendah, E. K. (2019). KONSEP KEADILAN EKOLOGI DAN KEADILAN SOSIAL DALAM SISTEM HUKUM INDONESIA ANTARA IDEALISME DAN REALITAS. Jurnal 
Komunikasi Hukum (JKH), 5(2), 139. https://doi.org/10.23887/jkh.v5i2.18425

Ramadhan, D., Darmawan, W., \& Iriyadi, A. (2017). HJALMAR SCHACHT, SANG

DIKTATOR PEREKONOMIAN JERMAN (Sebuah Tinjauan Historis). FACTUM: Jurnal

Sejarah Dan Pendidikan Sejarah, 6(1), 30.

https://doi.org/10.17509/factum.v6i1.10015

Rice, J. D. (2018). Early American Environmental Histories. JSTOR, 75(3), 401-432.

Retrieved from

https://www.jstor.org/stable/10.5309/willmaryquar.75.3.0401?Search=yes\&resul tItemClick=true \&searchText=American

Black\&searchUri=\%2Faction\%2FdoBasicSearch\%3FQuery\%3DAmerican\%2BBlack \%26sd\%3D2017\%26ed\%3D2021\&ab_segments=0\%2Fbasic_search_gsv2\%2Fcont rol\&refreq

Rumahorbo, H. (2020). KETELADANAN TANGGUNG JAWAB YESUS SEBAGAI GEMBALA MENJADI DASAR PELAYANAN HAMBA TUHAN MASA KINI. Phronesis: Jurnal Teologi Dan Misi, 3(2), 130-146. https://doi.org/10.47457/phr.v3i2.68

Samarenna, D. (2019). Tinjauan Teologi “Allah Kota Benteng” Dalam Mazmur 46:1-12. PASCA : Jurnal Teologi Dan Pendidikan Agama Kristen, 15(2), 15-21. https://doi.org/10.46494/psc.v15i2.53

Sholahudin, U. (2019). KEADILAN HUKUM BAGI SI MISKIN : Sebuah Elegi Si Miskin Dihadapan Tirani Hukum. Journal of Urban Sociology, 1(1), 35.

https://doi.org/10.30742/jus.v1i1.562

Siagian, R. J. (2019). Telaah Kritis Konstruktif Struktur dan Isi Pemahaman Bersama Iman Kristen dalam Perspektif Lutheran. EPIGRAPHE: Jurnal Teologi Dan Pelayanan Kristiani, 3(1), 53. https://doi.org/10.33991/epigraphe.v3i1.51

Siahaan, H. E. R. (2017). Karakteristik Pentakostalisme Menurut Kisah Para Rasul. DUNAMIS: Jurnal Penelitian Teologi Dan Pendidikan Kristiani, 2(1), 12. https://doi.org/10.30648/dun.v2i1.132

Siahaan, H. E. R. (2018). Memaknai Pentakostalisme dalam Maksud Politis Lukas: Analisis Kisah Para Rasul 1:6-8. DUNAMIS: Jurnal Teologi Dan Pendidikan Kristiani, 3(1), 37. https://doi.org/10.30648/dun.v3i1.178

Stone, S. (2018). Pentecostal power: discipleship as political engagement. Journal of the European Pentecostal Theological Association, 38(1), 24-38. https://doi.org/10.1080/18124461.2018.1434727

Sulistyorini, S. (2020). Pancasila as a Paradigm for Modern Indonesia Defense. Social Sciences, Humanities and Education Journal (SHE Journal), 1(1), 32. https://doi.org/10.25273/she.v1i1.5856

Suliyati, T. (2018). JUGUN IANFU : DERITA PEREMPUAN DALAM PUSARAN PERANG. Kiryoku Jurnal Studi Kejepangan, 2(3), 159-167. https://doi.org/10.14710/kiryoku.v2i3.41-49

Sunarko, A. S. (2019). Keadilan, Demokrasi dan HAM dalam Perspektif Pentakosta. HARVESTER Jurnal Teologi Dan Kepemimpinan Kristen, 4(1), 64-73. https://doi.org/https://doi.org/10.52104/harvester.v4i1.7 
Sutoyo, D. (2018). Analisis Historis terhadap Teologi Gerakan Pentakostalisme. DUNAMIS: Jurnal Teologi Dan Pendidikan Kristiani, 2(2), 167. https://doi.org/10.30648/dun.v2i2.171

Toganti, B. Z. (2019). Kriteria Pemimpin Jemaat Menurut Titus 1:5-9. JURNAL TERUNA BHAKTI, 1(1), 42. https://doi.org/10.47131/jtb.v1i1.10

Utomo, S. (2020). TANTANGAN HUKUM MODERN DI ERA DIGITAL. JURNAL HUKUM MEDIA BHAKTI, 1(1), 74-81. https://doi.org/10.32501/jhmb.v1i1.5

van Ommen, A. L. (2019). Communities of Restoration: Ecclesial Ethics and Restorative Justice. By Thomas Noakes-Duncan. The Journal of Theological Studies, 70(2), 954957. https://doi.org/10.1093/jts/flz140

von Sinner, R. (2012). Yong, Amos, In the Days of Caesar: Pentecostalism and Political Theology. PENTECOSTUDIES: An Interdisciplinary Journal for Research on the Pentecostal and Charismatic Movements, 11(1), 115-117. https://doi.org/10.1558/ptcs.v11i1.115

Wagner, T. (2019). Contingency or Divine Justice: What Matters in Job's Fate? Synchronic Perspectives on Prologue and Dialog in the Book of Job. Religions, 10(3), 149. https://doi.org/10.3390/rel10030149

Wijaya, H. (2016). Pengenaan Manusia Baru Di Dalam Kristus: Natur, Proses, Dan Fakta Serta Implikasi Teologis Dan Praktisnya. Jurnal Jaffray, 14(1), 109. https://doi.org/10.25278/jj71.v14i1.194

William Oliverio, L. (2020). Contours of a constructive pentecostal philosophicaltheological hermeneutic. Journal of Pentecostal Theology, 29(1), 35-55. https://doi.org/10.1163/17455251-02901003

Wood, L. J. (2005). The Prophets of Israel. Malang: Gandum Mas.

Xiao, A. (2018). KONSEP INTERAKSI SOSIAL DALAM KOMUNIKASI, TEKNOLOGI, MASYARAKAT. Jurnal Komunika : Jurnal Komunikasi, Media Dan Informatika, 7(2), 94-99. https://doi.org/10.31504/komunika.v7i2.1486

Yudho, W., \& Tjandrasari, H. (2017). EFEKTIVITAS HUKUM DALAM MASYARAKAT. Jurnal Hukum \& Pembangunan, 17(1), 57. https://doi.org/10.21143/jhp.vol17.no1.1227

Zaluchu, S. (2018). Sudut Pandang Etika Kristen Menyikapi Pembangkangan Sipil (Civil Disobedience). DUNAMIS: Jurnal Teologi Dan Pendidikan Kristiani, 3(1), 24. https://doi.org/10.30648/dun.v3i1.176

Zaluchu, S. E. (2020). Strategi Penelitian Kualitatif dan Kuantitatif Di Dalam Penelitian Agama. Evangelikal: Jurnal Teologi Injili Dan Pembinaan Warga Jemaat, 4(1), 28. https://doi.org/10.46445/ejti.v4i1.167

Zaluchu, S. E. (2021). Metode Penelitian di dalam Manuskrip Jurnal Ilmiah Keagamaan. Jurnal Teologi Berita Hidup, 3(2), 249-266. https://doi.org/10.38189/jtbh.v3i2.93 